\title{
VOLTAGE DISTURBANCES MITIGATION USING PSO BASED DVR CONTROLLER IN SIMPLIFIED ‘ABC’ FRAME IN DISTRIBUTION SYSTEMS
}

\author{
DR. S. VIJAYA LAXMI ${ }^{1} \&$ MRS. G. JAYA LAXMI ${ }^{2}$ \\ ${ }^{I}$ Associate Professor, Dept of EEE, Usharama College of Engineering \& Technology, Andhra Pradesh, India \\ ${ }^{2}$ Assistant Professor, Dept of EEE, Usharama College of Engineering \& Technology, Andhra Pradesh, India
}

\begin{abstract}
The voltage sag and swell in the medium and low voltage distribution grid are considered to be the most frequent type of power quality problems based on recent power quality studies. Their impact on sensitive loads is severe. For sensitive loads, even voltage sag of short duration can cause serious problems in the entire system. Normally, a voltage interruption triggers a protection device, which causes shutdown of the entire system. The work presented in this paper is confined to voltage quality identification and mitigation for sag and swell. The work carried out concentrates on the development of simplified suitable devices for mitigation of voltage sag and swell. Many of the suitable devices such as D-STATCOM, UPQC and DVR are available to mitigate voltage sag and swell problems. Among these, Dynamic Voltage Restorer (DVR) can provide the most commercial solution to mitigate voltage sag by injecting voltage as well as power into the system. Dynamic Voltage Restorer is a series connected power electronics based device that can quickly mitigate the voltage sag and swell in the system and restore the load voltage. Energy storage devices used in this work Battery for DVR and it is responsible for supplying active power needed during voltage sag and swell. In this work control objective like, simple abc control algorithm based PSO is proposed. It is to utilize the error signal to control the triggering of the switches of an inverter using Pulse Width Modulation (PWM) technique. Modeling and simulation of proposed DVR control is implemented in MATLAB /SIMULINK software and results are presented.

KEYWORDS: Power Quality, Voltage Disturbance, Mitigation of Sag And Swell, DVR and PSO Algorithm
\end{abstract}

Received: May 15, 2020; Accepted: Jun 05, 2020; Published: Jun 30, 2020; Paper Id.: IJMPERDJUN2020289

\section{INTRODUCTION}

The power quality problems occur due to voltage disturbances in the system, caused by electrical system faults, switching of large loads or energization of transformers etc. Such voltage disturbances cause short term rapid changes in amplitude of voltage. These voltage changes such as temporary voltage rise (swell) or voltage reduction (sag) are more frequent and have severe impact on the power system. Among the various custom power devices, the DVR is the most suitable one due to its low cost and simplicity in operation. In this paper, The control strategy used for DVR is PSO based algorithm with Simplified abc theory and this technique is used to improve the performance of DVR which is considered and analysed for its performance $[1,2]$. The control strategy for extracting the compensation voltage in DVR is based on Simplified abc theory along with a PSO controller for generating gate pulses for the VSC. This paper illustrates PSO based DVR controller in simplified abc frame. Battery which is used as energy storage unit of DVR. This Battery unit improves compensation capability of DVR when large voltage sag and swell occur as compared to, flywheel diodes and uninterrupted power supply[3,4]. Particle swarm optimization (PSO) theory based DVR with SMES unit and Matlab/Simulink based models are developed and performance is 
obtained by simulation results.

\section{PARTICLE SWARM OPTIMIZATION (PSO) OPERATION}

Particle swarm optimization (PSO) is a computational method that optimizes a problem by iteratively trying to improve a candidate solution with regard to a given measure of quality. It solves a problem by having a population of candidate solutions, here dubbed particles, and moving these particles around in the search- space according to simple mathematical formulae for the particle's position and velocity. Each particle's movement is influenced by its local best known position but is guided towards the best known positions in the search-space, which are updated as better positions found by other particles. This is expected to move the swarm towards the best solutions. Particle Swarm Optimization (PSO) is a population based stochastic optimization technique inspired by social behaviour of bird flocking or fish schooling. The movements of the birds are reflected and called as movements of "particle". All particles have fitness values which are evaluated by the fitness function to be optimized and have velocities which direct the flying of the particles. In this work the proposed objective function is minimization of magnitudes of voltage sag and swell.[5,6]

In this the gains $\mathrm{Kp}$ and Ki of PI controller are tuned by the PSO algorithm. Fig.1 shows the PI -PSO Control System.

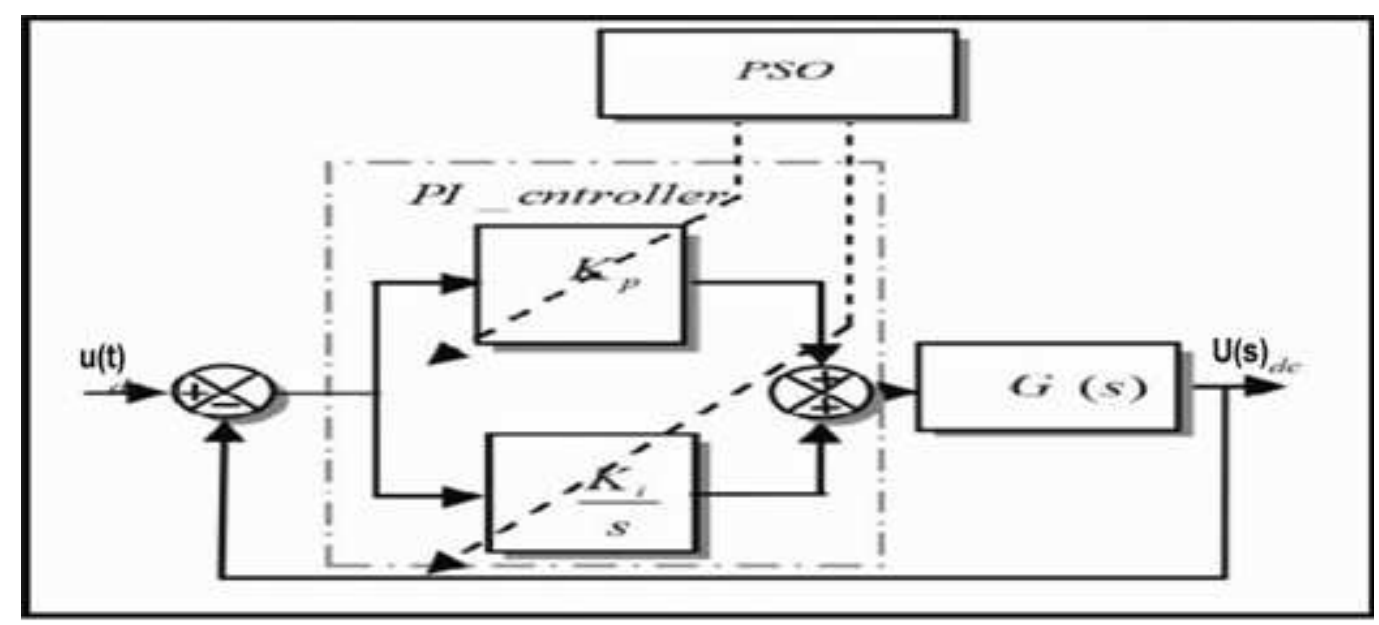

Figure 1: PI -PSO Control System.

The output of the PI controller ( $t$ ) is given by:

$$
\begin{aligned}
& \mathrm{u}(\mathrm{t})=\mathrm{k}_{\mathrm{p}} \mathrm{e}(\mathrm{t})+\mathrm{k}_{\mathrm{i}} \mathrm{fte}(\mathrm{t}) \mathrm{dt} \\
& V_{i}^{k+1}=V_{i}^{k}+C_{1} \times \operatorname{ran}\left(\phi_{1}\right) \times\left(\text { pbeşt } S_{i}^{k}\right)+C_{2} \times \operatorname{ran}\left(b_{2} \times\left(\text { gbest } S_{i}^{k}\right)\right. \\
& S_{i}^{k+1}=S_{i}^{k}+V_{i}^{k+1}
\end{aligned}
$$

Where

$$
\begin{aligned}
& V_{i}^{k+1}: \text { Velocity of particle } i \text { at iteration } k+1 \\
& V_{i}^{k}: \text { Velocity of particle } i \text { at iteration } k
\end{aligned}
$$




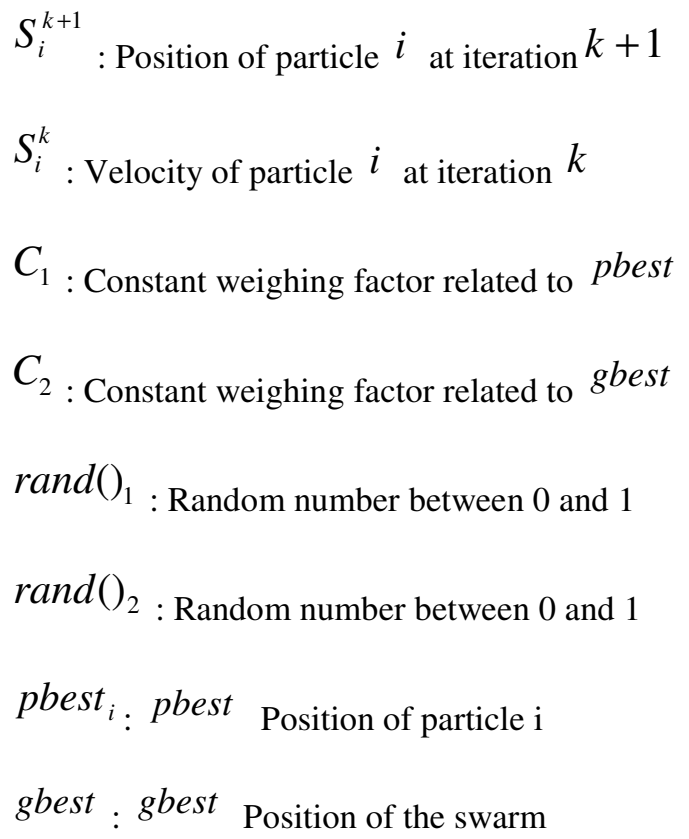

Expressions (1) and (2) describe the velocity and position update, respectively. Expression (1) calculates a new velocity for each particle based on the particle's previous velocity, the particle's location at which the best fitness has been achieved so far, and the population global location at which the best fitness has been achieved so far.

There are not many parameters that need to be tuned in PSO. Here is a list of the parameters and their typical values.

The number of particles: The typical range is 20 - 40. Actually for most of the problems 10 particles is large enough to get good results. For some difficult or special problems, one can try 100 or 200 particles as well.

Dimension of particles: It is determined by the problem to be optimized

Range of particles: It is also determined by the problem to be optimized and different ranges can be specified for different dimensions of particles.

$V_{\text {max }}$ : it determines the maximum change in velocity one particle can take during for one iteration.

Learning factors: $\mathrm{c}_{1}$ and $\mathrm{c}_{2}$ usually equal to 2 . However, other settings are also used in different papers. But usually $c_{1}$ equals to $c_{2}$ and ranges from $[0,4]$.

The stop condition: The maximum numbers of iterations the PSO execute and the minimum error requirement or the maximum number of iterations depends on the problem to be optimized.

Later, in order to improve PSO performance, a linear decreasing weight (LDW) parameter called inertia weight is developed and introduced by Shi and Eberhart .

s brought in for balancing the global and local search and is shown in equation (6.3)

w is the inertia weight. Suitable selection of inertia weight 'w' provides a balance between global and local explorations, thus requiring less iteration on the average to find a sufficiently optimal solution. As originally developed, w 
often decreases linearly from about 0.9 to 0.4 during a run. In general, the inertia weight w is set according to the following equation,

$$
\mathrm{w}=\mathrm{w}_{\max }-\frac{\left(\mathrm{w}_{\max }-\mathrm{w}_{\text {min }}\right) \times \text { iter }}{\text { iter }_{\max }}
$$

Where iter :current iteration number

iter $_{\max } \quad$ :maximum number of iterations

In the iteration process the particle velocity is limited by some maximum value $v_{i}^{\max }$. The parameter $v_{i}^{\max }$ determines the resolution, or fitness, with which regions are to be searched between the present position and the target position. This limit enhances the local exploration of the problem space and it realistically simulates the incremental changes of human learning. If $v_{i}^{\max }$ is too high, particles might fly past good solutions. If $v_{i}^{\max }$ is too small, particles may not explore sufficiently beyond local solutions. In many experiences with PSO, $v_{i}^{\max }$ is often set at $10 \%-20 \%$ of the dynamic range of the variable on each dimension.

\section{SIMPLIFIED ABC FRAME BASED PSO CONTROL THEORY}

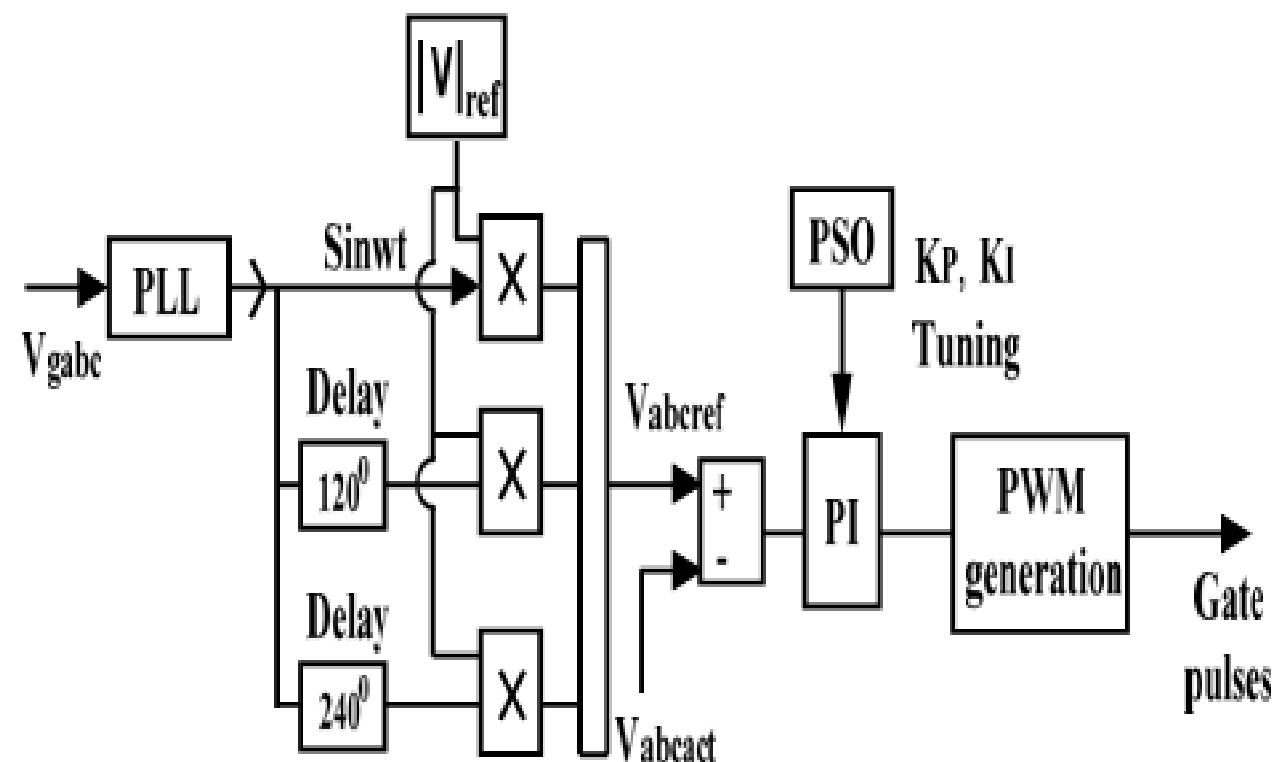

Figure 2: Simplified ‘abc' Frame Based PSO Control Theory.

The control strategy used for DVR is PSO based algorithm with Simplified abc theory and this technique is used to improve the performance of DVR. Fig.2 shows the control strategy of DVR with simplified 'abc' frame based PSO theory. The actual source voltage $\mathrm{V}_{\text {cabc }}$ is sensed and given to PLL which generates three phase components which are multiplied by the reference voltage. Final signal is sensed through PI controller. Tuned proportion and integral gains of PI controller are obtained using particle swarm optimization (PSO). This type of controller has benefits such as requires less processing time; size of controller is reduced and available in less cost compared to SRF controller. The controller output is given as an input to PWM generator block which generates the require gate pulses for VSI which is injected at PCC through injecting transformer connected in series to the power distribution line. It is seen that the load voltage is maintained constant. 


\section{DVR WITH PSO BASED PROPOSED SIMPLIFIED 'ABC' ALGORITHM}

Fig.3. shows block diagram of DVR with simplified 'abc' frame based PSO theory .The control strategy is implemented for DVR based PSO algorithm in simplified abc theory and the DVR performance is analyzed.

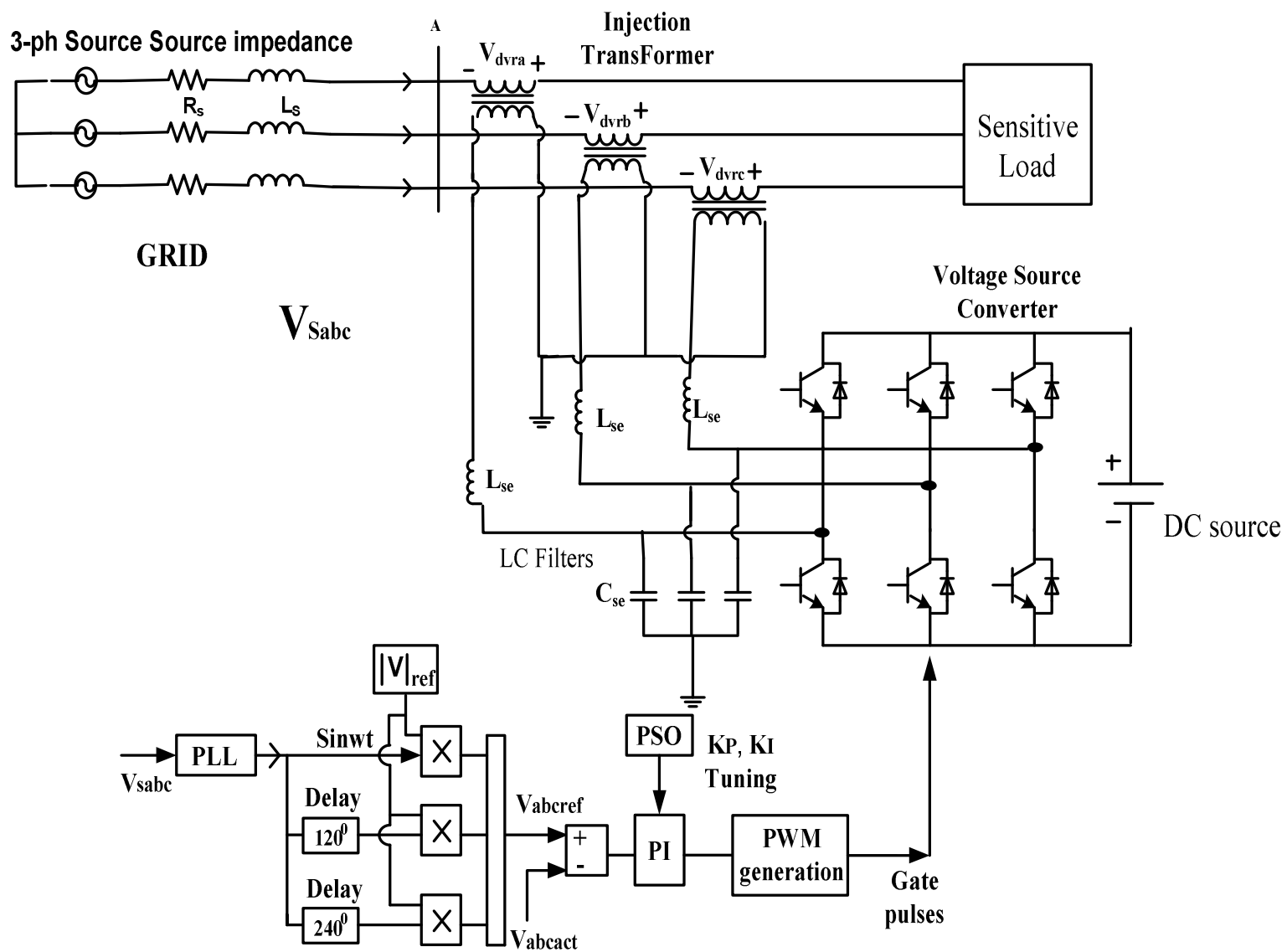

Figure 3: Block Diagram of DVR with Simplified 'abc' Frame Based PSO Theory.

\section{MATLAB/SIMULATION RESULTS AND DISCUSSIONS}

The performance of PSO based DVR controller in abc frame is implemented on a typical power distribution diagram and simulate is presented in fig.4. The simulation results are shown in figures 5.to 7.for different fault cases. Dynamic voltage restorer handles different fault conditions like single phase fault, two phase fault and three phase fault without any difficulties and injects the suitable voltages to maintain the balanced supply voltages during any of the above faulty situations in order to maintain the balanced load voltage at the nominal value. The DVR has shown the ability to perform mitigation for supply side voltage sag and swell which are proved through MATLAB/SIMULATION. The effectiveness in voltage sag and swell mitigation is improved by the DVR with greater efficiency which makes it an attractive custom power device and results are shown at different test cases of the system. 


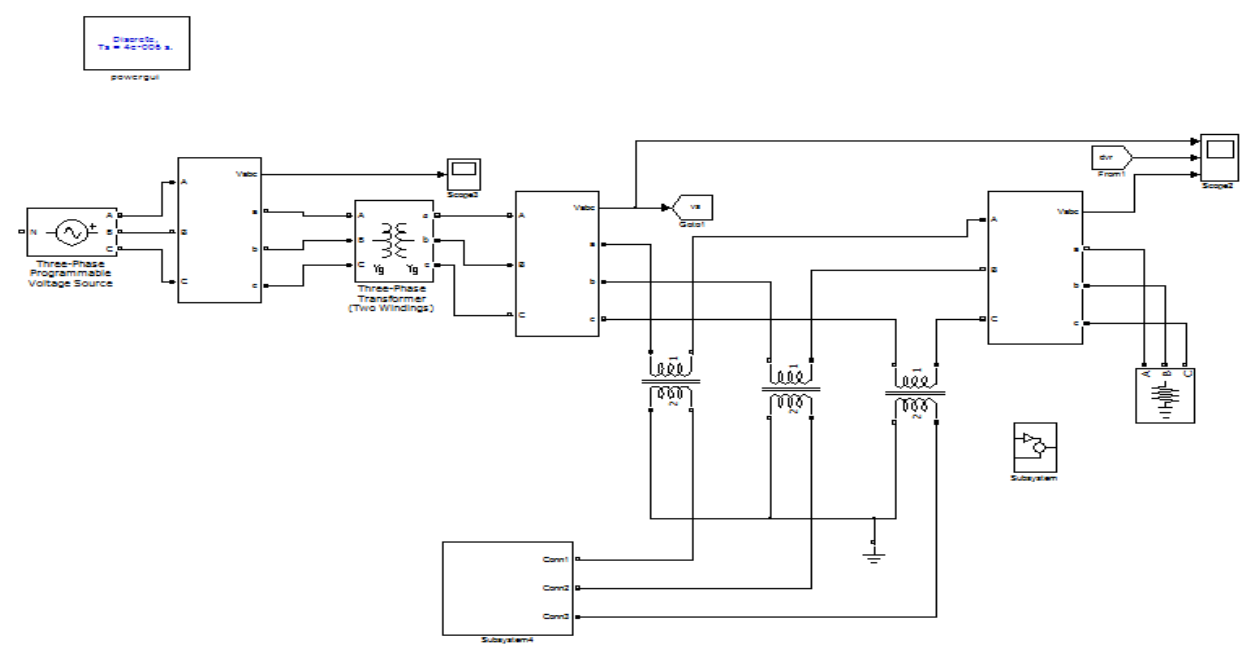

Figure 4: Simulation Diagram for Mitigation of Voltage Sag and Swell using DVR with PI-PSO Based Simple abc Algorithm.

Table 1: Sag in Three Phases of the System

\begin{tabular}{|c|}
\hline RESULT \\
\hline NOMINAL VOLTAGE $=\mathbf{4 4 0 v}$ \\
\hline SAG IN THREE PHASES $=300 \mathrm{v}$ \\
\hline SAG DURATION IN THREE PHASES WITHOUT AND WITH SMES $=\mathbf{0 . 1}$ to \\
0.15sec \\
\hline SAG DEPTH IN THREE PHASES $=0.68 \mathrm{pu}$ \\
\hline
\end{tabular}

CASE 1: Mitigation of Sag in Three Phases of a System

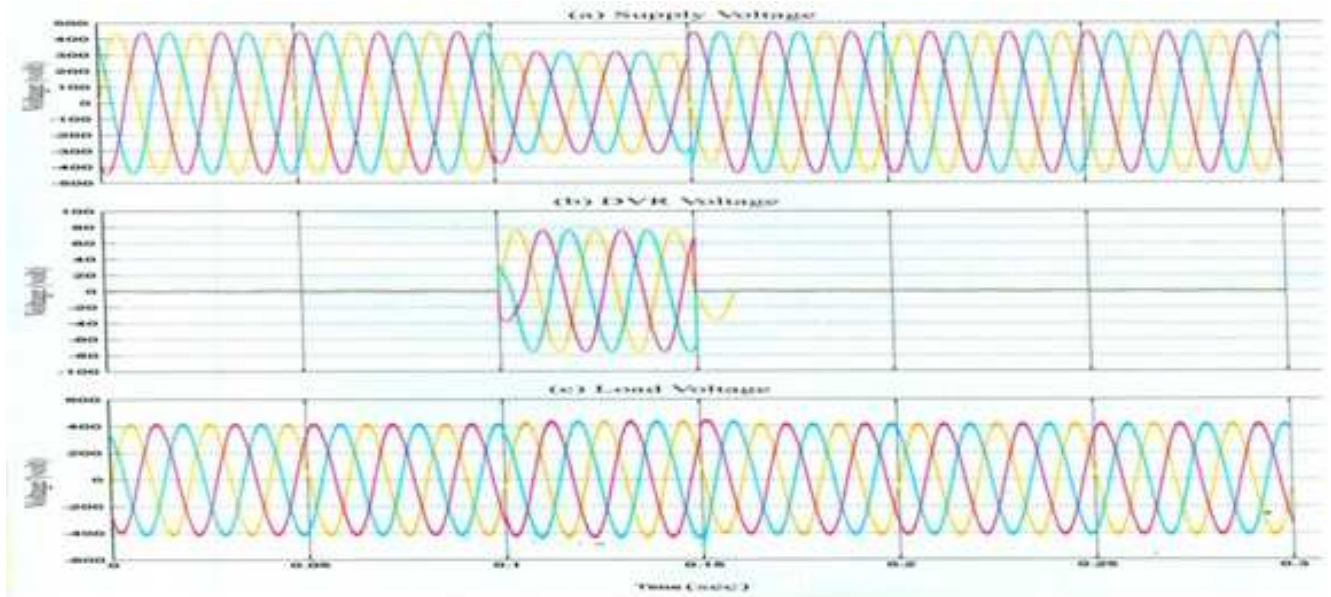

(a) Source Voltage (b) DVR Voltage (c) Load Voltage

Figure 5: Results for Three Phases Sag Condition without SMES.

The Matlab/simulation results of the DVR with PI-PSO controller for voltage sag condition of depth 0.68pu in three phases occurring for a duration from $0.1 \mathrm{sec}$ to $0.15 \mathrm{sec}$ due to (LLL-G) fault in the system is given in figure 5 . Fig.5 (a) shows the RMS voltage waveform of the source voltage of the system. Fig, (b) indicates the injected voltage by DVR which is nothing but the mitigation voltage. The third waveform (c) denotes the voltage present across sensitive load which is equal to source voltage plus voltage injected by DVR. It is seen that the load voltage is maintained constant by DVR. 
Table 2: Swell in Three Phases

\begin{tabular}{|c|}
\hline RESULT \\
\hline NOMINAL VOLTAGE $=440 \mathrm{v}$ \\
\hline SWELL IN THREE PHASES $=500 \mathrm{v}$ \\
\hline SWELL DURATION IN THREE PHASES $=0.1$ to 0.15sec \\
\hline SWELL DEPTH IN THREE PHASES $=1.13 \mathrm{pu}$ \\
\hline
\end{tabular}

CASE 3: Mitigation of Swell in Three Phases of the System

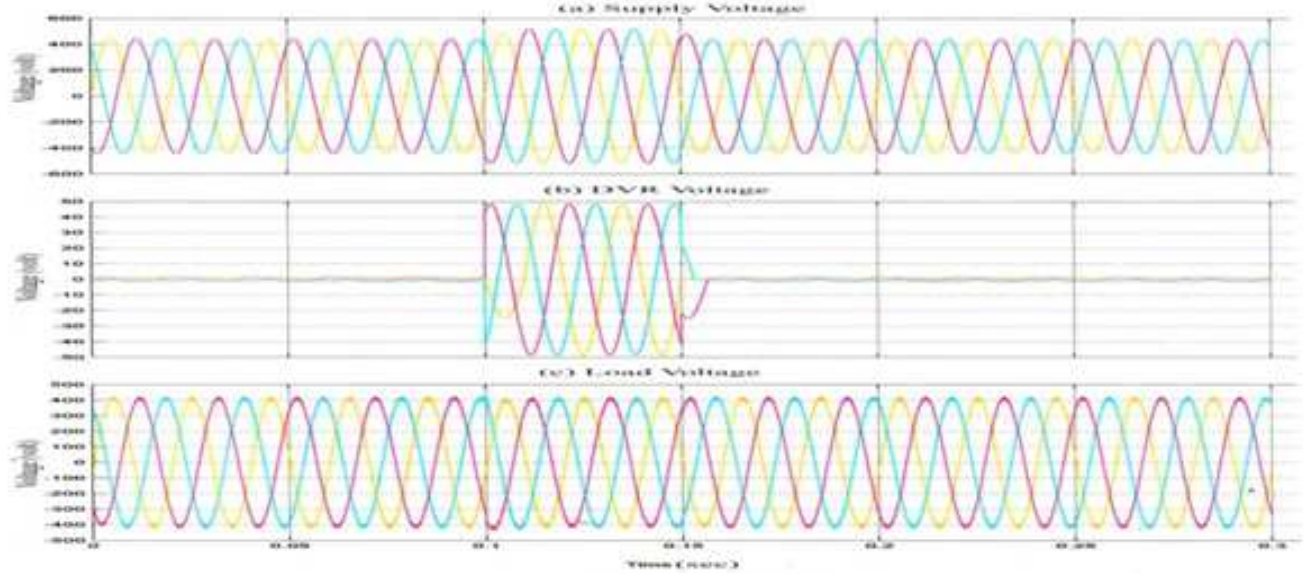

(a) Source Voltage (b) DVR Voltage (c) Load Voltage

Figure 6: Results for Three Phases Swell Condition without SMES.

The Matlab/simulation results of the DVR with PI-PSO controller for voltage sag and swell condition of depth $1.13 \mathrm{pu}$ in three phases occurring for a duration from $0.1 \mathrm{sec}$ to $0.15 \mathrm{sec}$ due to switching ON large capacitor banks in the system is given in fig.6. Fig 6 (a). Shows RMS voltage waveform of the source voltage of the system. Fig (b) indicates absorbed voltage by DVR which is nothing but the mitigation voltage. The fig (c) denotes the voltage present across sensitive load. It is seen that the load voltage is maintained constant by DVR.

Table 3: Multiple Sag and Swell in Three Phases of the System

\begin{tabular}{|c|}
\hline RESULT \\
\hline NOMINAL VOLTAGE $=\mathbf{4 4 0 v}$ \\
\hline SAG IN THREE PHASES $=340 \mathrm{v}$ \\
\hline SAG DURATION IN THREE PHASES $=0.1$ to $0.2 \mathrm{sec}$ \\
\hline SAG DEPTH IN THREE PHASES $=0.77 \mathrm{pu}$ \\
\hline SWELL IN THREE PHASES $=540 \mathrm{v}$ \\
\hline SWELL DURATION IN THREE PHASES $=0.25$ to $0.2 \mathrm{sec}$ \\
\hline SWELL DEPTH IN THREE PHASES $=1.2 \mathrm{pu}$ \\
\hline
\end{tabular}


CASE 5: Mitigation of Sag and Swell in Three Phases of the System without SMES

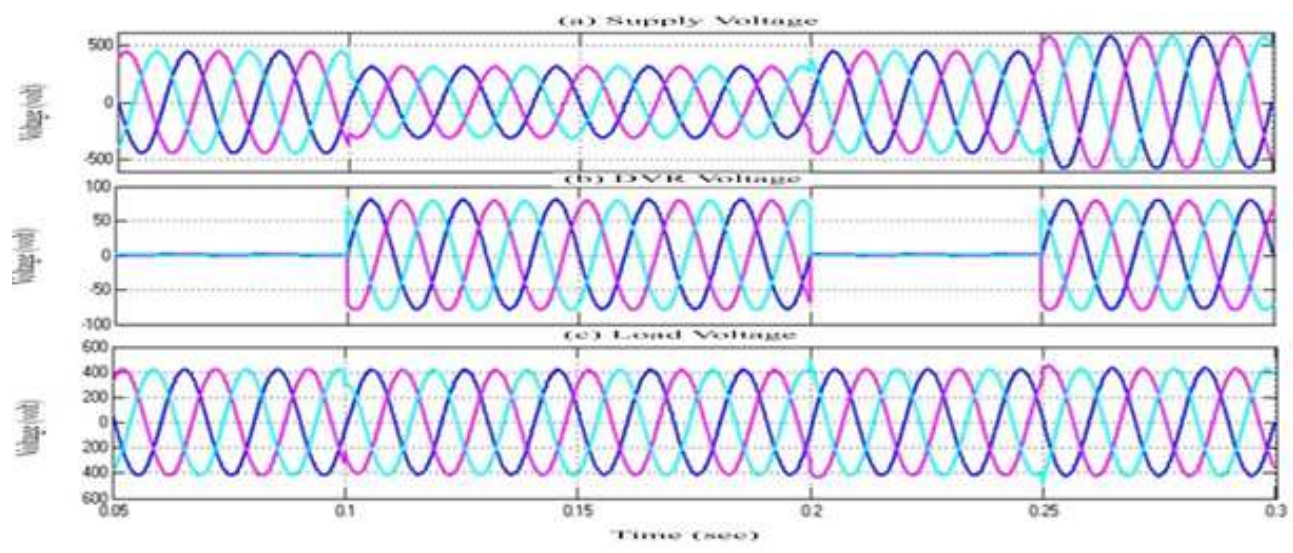

(a) Source Voltage (b) DVR Voltage (c) Load Voltage

Figure 7: Results for Multiple Three Phases Sag and Swell Conditions.

The Matlab/simulation results of the DVR with PI-PSO controller for multiple voltages sag and swell condition of depth $0.77 \mathrm{pu}$ and $1.2 \mathrm{pu}$ in three phases occurring for duration from $0.1 \mathrm{sec}$ to $0.2 \mathrm{sec}$ and 0.25 to $0.3 \mathrm{sec}$ due to LLL-G and switching ON large capacitor banks in the system respectively is given in fig.7. Fig 7 (a) shows RMS voltage waveform of the source voltage of the system. Fig (b) indicates absorbed voltage by DVR which is nothing but the mitigation voltage. The fig (c) denotes the voltage present across sensitive load. It is seen that the load voltage is maintained constant by DVR.

\section{CONCLUSIONS}

In this paper the design of the DVR with simplified abc based PSO theory control strategy is presented to compensate voltage disturbances. Tuned proportional and integral gains of PI controller have been obtained using particle swarm optimization (PSO). The simulation shows that DVR performance is satisfactory in mitigating voltage fluctuations. The proposed control strategy provides perfect control for DVR under large sag and swell. The performance of DVR along with PI-PSO controller is implemented on a typical power distribution system and the simulation results are shown in figures 5 to 7.for different fault cases. The DVR has shown the ability to perform mitigation for supply side disturbances like large voltage sag/ swell, multiple sag and swell which are proved through MATLAB/SIMULATION. Proposed work is carried out using MATLAB/SIMULINK software and results are presented. DVR is presented along with results and found to be very effective for large sag and swell conditions.

\section{REFERENCES}

1. U. T. Patil; A. R. Thorat; "Hysteresis Voltage Control Technique in Dynamic Voltage Restorer for Power Quality Improvement" 978-1-4673-6150-7/13/\$31.00 @2013 IEEE.

2. Lim PK, Dor DS. Understanding and resolving voltage sag related problems for sensitive industrial customers. IEEE Power Eng Soc Winter Meet 20011; 4:2886-90.

3. J.B. Park, K.S. Lee, J.R. Shin, and K.Y. Lee, "A particle swarm optimization for economic dispatch with non smooth cost functions,” IEEE Trans. on Power Systems, Vol. 20, No. 1, pp. 34-42, Feb. 2005.

4. Eashwaramma, N., J. Praveen, and M. Vijayakumar. "Modelling and Designing of Cascaded 9 Level Voltage Source Converter Based on DVR for Mitigating Harmonics in Distributed Power System Using Unit Vector." International Journal of Electrical and Electronics Engineering Research (IJEEER) 8.1 (2018): 11-20. 
5. Y. W. Li, D. M. Vilathgamuwa, F. Blaabjerg, and P. C. Loh, "A robust control scheme for medium-voltage-level DVR implementation," IEEE Trans. Ind. Electron., Vol. 54, No. 4, pp. 2249-2261, Aug. 2007.

6. A K. Sadigh and K. M. Smedley, "Review of voltage compensation methods in dynamic voltage restorer (DVR)," in Proc. IEEE Power Energy Soc. Gen. Meet., Jul. 2012, pp. 1-8

7. Ali, Syed Yasser, and K. Suneeta. "Simulation of the hysteresis voltage control technique in the pv based dynamic voltage restorer for power quality improvement with induction motor drive." International Journal of Electrical and Electronics Engineering Research (IJEEER) 5.1 (2015): 95-106.

8. G Lambert-Torres, H.G.Martins, M.P. Coutinho, C.P. Salomon and F.C. Vieira," Particle Swarm Optimization Applied to System Restoration”, IEEE Trans. Bucharest Power Tech Conference, 2009.

9. Y. del Valle, J. C. Hernandez, G.K. Venayagamoorthy, and R.G. Harley, "Optimal STATCOM Sizing and Placement Using Particle Swarm Optimization,” Accepted by the IEEE PES Transmission and Distribution Conference and Exposition Latin America 2006, Caracas, Venezuela, 2006

10. Dr. T. Ruben; Deva Prakash; G.Justin; Sunil Dhas; "A Novel approach for Voltage Sag Mitigation Using FACTS Device Interline Dynamic Voltage Restorer"978-1-4244-8679-3/11/\$26.00@2011IEEE”

11. Reddy, V. K., et al. "Performance analysis of DSTATCOM compensator using control techniques for load compensation." Int. J. Electr. Electron. Eng. Res. 1.2 (2011): 149-171.

12. A Y. Goharrizi, S. H. Hosseini, M. Sabahi, and G. B. Gharehpetian, "Three-phase HFL-DVR with independently controlled phases," IEEE Trans. Power Electron., Vol. 27, No. 4, pp. 1706-1718, Apr. 2012.

13. E. Babaei M. Farhadi Kangarlu, _Voltage quality improvement by a dynamic voltage restorer based on a direct three-phase converter with fictitious DC linkl, IET Gener. Transm. Distrib., 2011, Vol. 5, Iss. 8, pp. 814-823.

14. Venkateswarlu, G., M. Pavan, and P. Raju. "Improvement of the Voltage Stability in the Distribution System by Using the Multifunctional Dynamic Voltage Restorer." International Journal of Electrical and Electronics Engineering (IJEEE) 3.1 (2014): 37-48.

15. D. Mahinda Vilathgamuwa, H. M. Wijekoon, and S. S. Choi, "A Novel technique to compensate voltage sags in multiline distribution system-The interline dynamic voltage restorer", IEEE Transactions on Industrial Electronics, Vol.53, No. 5, pp. 1603-161 1, October 2006. 

